\title{
PROTEINOGRAMA SÉRICO DE CORDEIROS MESTIÇOS (SANTA INÊS X DORPER) DO NASCIMENTO ATÉ O DESMAME: EFEITO DO DESENVOLVIMENTO ETÁRIO E DO MONITORAMENTO DA INGESTÃO DO COLOSTRO
}

\author{
Débora de Fátima Matias Silva, ${ }^{1}$ Joselito Nunes Costa, ${ }^{2}$ Alexandre Lôpo Araújo, ${ }^{3}$ \\ Antônio Oliveira Costa Neto, ${ }^{4}$ Maria Ângela Ornelas Almeida ${ }^{5}$ E Vitor Santiago Carvalho 6 \\ 1. Apoio técnico, Aperfeiçoamento em Buiatria, UFBA \\ 2. Professor adjunto do Departamento de Patologia e Clínicas e coordenador do Centro de Desenvolvimento da \\ Pecuária da Escola de Medicina Veterinária da Universidade Federal da Bahia. E-mail: ufbacdp@ufba.br \\ 3. Agência Estadual de Defesa Agropecuária da Bahia \\ 4. Professor assistente da Universidade Estadual de Feira de Santana \\ 5. Professor associado I da Universidade Federal da Bahia \\ 6. Professor substituto da Universidade Federal da Bahia.
}

\section{RESUMO}

A falha da transferência da imunidade passiva tem sido um grande obstáculo na ovinocultura e uma importante causa de enfermidades e mortalidades neonatais. Em busca de uma medida de manejo eficiente para sanar este problema, avaliou-se o efeito da idade e do monitoramento da administração do colostro na dinâmica do proteinograma sérico, utilizando-se 44 cordeiros divididos em dois grupos: ingestão de colostro monitorada (MO), contendo oito animais, e não monitorada (NM), com 36 animais, acompanhados com avaliação clínica, hemograma, determinação de proteínas séricas totais e seu fracionamento eletroforético $24-72 \mathrm{~h}$ após o nascimento, aos sete, quinze, trinta, sessenta e noventa dias de idade. $\mathrm{O}$ grupo $\mathrm{MO}$ foi acompanhado em dois momentos adicionais: antes da ingestão do colostro e seis horas após. A proteína total e a gamaglobulina $(\mathrm{g} / \mathrm{dL})$ no grupo $\mathrm{MO}$ apresentaram valores mínimos após o nascimento $(3,62 \pm 0,70$ e $0,32 \pm 0,12)$ e máximos às $24-72 \mathrm{~h}(7,98 \pm 1,95$ e 3,39 $\pm 1,13)$. Estas concentrações também apresentaram mesmo comportamento em NM, com valores menores $(5,57 \pm 1,45$ e $1,80 \pm 0,95)$, com diferença significativa $(p \leq 0,05)$ entre grupos. Entre quinze a trinta dias os valores destas variáveis apresentaram diminuição em ambos os grupos, e elevaram-se até noventa dias. Em todos os momentos experimentais, o grupo MO demonstrou valores de gamaglobulinas superiores aos de NM. Conclui-se que a maioria das frações proteicas sofre variação com o desenvolvimento etário, principalmente a proteína total e a gamaglobulina, e o monitoramento da mamada do colostro elevou significativamente os teores de gamaglobulinas.

PALAVRAS-CHAVES: Anticorpos endógenos, falha da transferência da imunidade passiva, gamaglobulinas, período neonatal, proteínas séricas.

\section{ABSTRACT}

\section{SERUM PROTEINOGRAM CONCENTRATION IN CROSSBRED LAMBS (SANTA INÊS X DORPER) FROM BIRTH UNTIL 90 DAYS OLD: EFFECT OF THE AGE AND MONITORING OF COLOSTRUM INGESTION}

The failure of passive immunity transfer, which has been a major obstacle in the sheep industry, is an important cause of neonatal diseases and mortality. In search of an effective management measure to solve this problem, the effects of the age and the monitoring of colostrum administration on the dynamics of the serum proteins were evaluated. Forty-four lambs were used and divided into two groups: monitored colostrums intake (MO), with 8 animals, and non-monitored colostrums intake (NM), with 
36 animals, along with clinical evaluation, hemogram and total serum protein assessment and its electrophoretic fractioning, 24-72h after birth, at 7, 15, 30, 60 and 90 days of age. The MO group was followed in two additional times: before and six hours after colostrum intake. Total protein and gammaglobulin $(\mathrm{g} / \mathrm{dL})$ in the MO group presented the minimum values right after birth (3.62 \pm 0.70 and $0.32 \pm 0.12$ ) and the maximum 24-72 hours after birth $(7.98 \pm 1.95$ and $3.39 \pm 1.13)$. Such concentrations also showed the same behavior in the NM group, with lower values
$(5.57 \pm 1.45$ and $1.80 \pm 0.95)$, and with significant difference (p $\leq 0.05$ ) between groups. Between 15 to 30 days, the values of these variables decreased in both groups, and increased up to 90 days. In all experimental moments, the MO group showed higher values of gammaglobulin than NM group. The conclusions of this paper are that most of protein fractions, mainly total protein and gammaglobulin, undergo changes with the age development, and that the monitoring of colostrum intake increased significantly the levels of gammaglobulin.

KEYWORDS: Endogenous antibodies, failure of passive immunity transfer, immunoglobulins, neonatal period, serum proteins.

\section{INTRODUÇÃO}

As proteínas são compostos indispensáveis à vida, representando a base da estrutura de células, tecidos e órgãos. Pelo significado biológico e múltiplas funções exercidas no sistema orgânico, a avaliação dos teores séricos das proteínas totais e de suas frações (albumina, alfaglobulinas, betaglobulinas e gamaglobulinas) obtidas por eletroforese representa um importante auxílio ao diagnóstico clínico (RIZZOLI et al., 2006).

$\mathrm{O}$ metabolismo e as concentrações de proteínas presentes no soro de animais neonatos podem sofrer influência de diversos fatores, entre os quais é relevante destacar a mamada do colostro e a idade. Imediatamente após o nascimento, são observadas concentrações mínimas de proteínas e, após a ingestão do colostro, em virtude da absorção intestinal de macromoléculas (imunoglobulinas), nota-se uma elevação no total de proteínas (RIZZOLI et al., 2006). Após esse período há o catabolismo das imunoglobulinas adquiridas passivamente, o que reflete numa gradativa diminuição das taxas séricas de proteínas, até verificar-se uma estabilização, ou seja, o início da produção de suas próprias imunoglobulinas por parte do neonato (LEAL et al., 2003).

Além disso, vários outros fatores podem influenciar o perfil eletroforético das proteínas séricas dos ruminantes. Estes variam desde o sistema de criação, fatores ambientais e de manejo, até a técnica utilizada (SANTAROSA et al., 2005). Logo, é necessária a padronização dos valores normais do proteinograma, bem como das alterações fisiológicas e patológicas de cada espécie animal (KEAY \& DOXEY, 1982).

Os neonatos ruminantes são mais expostos às infecções no período do nascimento até que seu sistema imunológico passe a responder eficientemente aos desafios do meio ambiente. Essa susceptibilidade deve-se também à placenta do tipo epiteliocorial, que não permite a passagem transplacentária de anticorpos. Sendo assim, é necessária uma imediata ingestão do colostro, de forma que os anticorpos sejam transferidos passivemente. CONSTANT et al. (1994) verificaram relação entre diminutas concentrações de imunoglobulinas e perdas de cabritos por causas infecciosas relacionadas a uma condição de falha na transferência passiva da imunidade (FTP). DOBBELAAR et al. (1987) observaram a interferência de vários fatores na concentração de gamaglobulinas séricas em bezerros recém-nascidos. Três fatores - o tempo da primeira ingestão do colostro, a quantidade de colostro ingerida e a concentração da gamaglobulina no primeiro colostro - explicam 19\% da variação da concentração da gamaglobulina sérica.

Além da função na imunidade neonatal, o colostro é uma importante fonte de proteínas, carboidratos, lipídeos, vitaminas e sais minerais. Trata-se de elementos que participam da nutrição e regulação térmica do recém-nascido. Assim, assegurar a ingestão precoce, e em quantidades adequadas de um colostro de boa qualidade, continua sendo a ferramenta de manejo mais importante para a sobrevivência e saúde dos neonatos ruminantes (FONTES et al., 2007).

A amamentação natural é o método de ingestão do colostro mais eficaz, porém é influenciado pela capacidade de mamar e pelo vigor do animal ao nascer. A sucção natural é comumente associada a uma taxa elevada de insuficiência na transferência passiva, em virtude da demora em mamar, associada a pouca ingestão. $\mathrm{O}$ volume de colostro administrado na primeira mamada exerce influência direta na massa das imunoglobulinas ingeridas. Em situação de amamentação natural, os animais podem deixar de ingerir volumes adequados de colostro, ocorrendo absorção deficiente das imunoglobulinas (SIMÕES et al., 2005). Assistência precoce ao 
lactente pode evitar esta ocorrência. Para minimizar a possibilidade de falha de transferência passiva das imunoglobulinas pode-se realizar a administração artificial do colostro por meio de mamadeira ou intubação esofágica. Pode-se também realizar o monitoramento do parto e da ingestão do colostro. A necessidade de colostro de um cordeiro recém-nascido corresponde a $10 \%$ a $20 \%$ do seu peso corporal e deve ser fornecido três a doze horas após o nascimento, uma vez que a absorção deste diminui rapidamente a partir do nascimento até trinta e seis horas de idade. Para suprir qualquer deficiência de colostro e evitar a ocorrência de falha da transferência de imunidade passiva, é possível utilizar colostro congelado e até lançar mão de colostro de outras espécies (ARGUELLO et al., 2004).

MACHADO NETO et al. (2004a) verificaram que o modo como o colostro é fornecido (na própria mãe, com o uso de mamadeira ou sonda esofágica) tem grande relevância na sobrevivência de neonatos ruminantes. $\mathrm{O}$ fornecimento artificial de colostro, praticado no tempo correto, em quantidades adequadas, com boas práticas de assepsia assegura a higidez do recémnascido e menores taxas de mortalidade. DANIELE et al. (1994) observaram que, além da proteção no que se refere à imunidade colostral, o fornecimento de colostro suplementar mostrou-se uma prática eficiente que confere maior proteção local contínua no lúmen intestinal de neonatos ruminantes e maximiza o desempenho dos animais.

Segundo SIMÕES et al. (2005), a avaliação da aquisição da imunidade passiva pode ser realizada através da dosagem da proteína sérica total e de suas frações antes e após a ingestão do colostro. Este procedimento permite quantificar a fração gama das globulinas absorvida, que incluem as imunoglobulinas. No entanto, a adequada concentração de gamaglobulinas no soro de cordeiros não tem sido suficientemente estudada, especialmente em cordeiros submetidos a diferentes manejos na fase de colostro.

Por ser de grande importância o conhecimento de valores séricos do proteinograma, sua utilização na medicina veterinária e a escassez de trabalhos brasileiros relacionados à espécie ovina e também reconhecendose a necessidade de se avaliar novas estratégias de manejo de colostro para garantir adequada aquisição de imunidade passiva, o objetivo deste estudo foi avaliar a influência do desenvolvimento etário e do monitora- mento da administração do colostro sobre a dinâmica do proteinograma sérico de cordeiros mestiços (Santa Inês $\mathrm{x}$ Dorper) de um rebanho comercial desde o nascimento até o desmame (noventa dias de idade).

\section{MATERIAL E MÉTODOS}

A pesquisa foi realizada em uma propriedade localizada no município de Santo Amaro da Purificação, BA, cuja atividade principal é a ovinocultura comercial. Utilizaram-se 44 cordeiros, machos e fêmeas, mestiços Santa Inês x Dorper, nascidos de mães pluríparas. As ovelhas que fizeram parte do experimento tiveram sua condição de saúde assegurada pelo exame clínico, hemograma e parasitológico de fezes. Os cordeiros foram acompanhados do nascimento até os noventa dias de idade.

As matrizes eram mantidas sob manejo de pastejo rotacionado em pastagens de Brachiaria decumbens, $B$. brizanta e $B$. humidicula durante o dia, sendo recolhidas para o curral no fim da tarde, onde recebiam sal mineral comercial ad libitum. A propriedade adota manejo reprodutivo de monta controlada. Aproximadamente um mês antes do parto as ovelhas eram separadas do rebanho e alocadas em piquete e curral maternidade, durante o dia e à noite, respectivamente. Após o parto era realizada a cura do umbigo do cordeiro com solução de iodo a $10 \%$, daí então a ovelha e seu cordeiro eram mantidos no aprisco durante as primeiras 24 horas. Nos dois dias subsequentes, tanto a ovelha quanto o cordeiro eram liberados juntos no piquete maternidade durante $o$ dia e eram presos também juntos no final da tarde. Após esse período, os cordeiros eram liberados juntamente com suas mães durante o dia, porém eram recolhidos em currais separados durante a noite. $O$ curral destinado a alocar os cordeiros era equipado com campânulas de aquecimento. Neste, os cordeiros começavam a receber uma ração complementar (composta por milho, farelo de soja e farelo de trigo), que era fornecida todos os dias, no final da tarde até o desmame. Após completarem trinta dias, os cordeiros eram transferidos para um curral maior e continuavam recebendo ração até os noventa dias, quando era realizado o desmame dos borregos. O experimento foi desenvolvido de abril de 2006 a fevereiro de 2007.

Os primeiros 36 cordeiros nascidos foram submetidos ao sistema de manejo já estabelecido na pro- 
priedade, nascendo no piquete ou no curral maternidade, de parto natural sem observação, permanecendo com suas mães e mamando o colostro ad libitum. Estes compuseram o grupo de mamada de colostro não monitorada (NM). O grupo de animais de mamada do colostro monitorada (MO) foi composto por oito cordeiros nascidos de partos assistidos, nos quais as ovelhas eram observadas desde o início dos sinais de parto, durante o evento do parto propriamente dito e no pós-parto imediato. Os cordeiros eram limpos pelas ovelhas e assim que ficavam de pé eram recolhidos para realização da cura do umbigo com solução de iodo a $10 \%$, avaliação clínica e colheita das amostras. Após isto, os cordeiros eram colocados juntamente com suas mães, sendo auxiliados para a realização da primeira mamada do colostro. Este auxílio era cessado somente quando o cordeiro já não apresentava mais apetite e era percebida distensão abdominal referente à boa quantidade de colostro ingerida. Após este procedimento, o cordeiro era mantido junto com a ovelha (colostro ad libitum) e, decorridas seis horas do nascimento, eram realizadas outra avaliação clínica e outra colheita de material.

Os cordeiros foram acompanhados até os noventa dias. O grupo NM foi submetido a seis momentos experimentais e o grupo $\mathrm{MO}$ foi submetido a oito momentos, como descrito no Quadro 1.

QUADRO 1. Momentos de análise dos grupos experimentais: aleitamento monitorado (MO) e aleitamento não monitorado (NM)

\begin{tabular}{|c|c|c|c|}
\hline Momento & Período & $\begin{array}{c}\text { Grupo } \\
\text { MO }\end{array}$ & $\begin{array}{c}\text { Grupo } \\
\text { NM }\end{array}$ \\
\hline MA & $\begin{array}{c}\text { Após o parto, quando o } \\
\text { cordeiro ficava de pé e antes } \\
\text { da primeira mamada. }\end{array}$ & $\mathrm{X}$ & - \\
\hline MB & Seis horas após o nascimento. & $\mathrm{X}$ & - \\
\hline M1 & $\begin{array}{c}\text { 24-72 horas após o } \\
\text { nascimento. }\end{array}$ & $\mathrm{X}$ & $\mathrm{X}$ \\
\hline M2 & $\begin{array}{c}\text { Sete dias após o nascimento. } \\
\text { Quinze dias após o } \\
\text { nascimento. }\end{array}$ & $\mathrm{X}$ & $\mathrm{X}$ \\
\hline M3 & $\begin{array}{c}\mathrm{X} \\
\text { M4 }\end{array}$ & $\begin{array}{c}\text { Trinta dias após o nascimento. } \\
\text { X }\end{array}$ & $\mathrm{X}$ \\
\hline M5 & $\begin{array}{c}\text { Sessenta dias após o } \\
\text { nascimento. }\end{array}$ & $\mathrm{X}$ & $\mathrm{X}$ \\
\hline M6 & $\begin{array}{c}\text { Noventa dias após o } \\
\text { nascimento. }\end{array}$ & $\mathrm{X}$ & $\mathrm{X}$ \\
\hline
\end{tabular}

Em todos os momentos experimentais realizavam-se avaliação clínica e colheita de sangue dos cordeiros.

As colheitas de sangue destes animais deramse através da punção da veia jugular após tricotomia e assepsia do local. Para as colheitas, utilizaram-se agulhas descartáveis (25×8), acopladas a canhão adaptador, e tubos estéreis a vácuo (Becton - Dixen, Vacutainer System, NJ) com e sem anticoagulante EDTA. Foram colhidas amostras de sangue com anticoagulante (EDTA), para determinação laboratorial do hemograma, e sem anticoagulante para obtenção de soro sanguíneo, mantido sob abrigo da luz e congelado a $-20^{\circ} \mathrm{C}$, para determinação das proteínas séricas totais e seu fracionamento eletroforético.

Determinou-se a proteína sérica total pelo método colorimétrico por reação com o biureto, utilizando-se reagentes comerciais (Doles, Goiânia, GO). A leitura foi realizada em espectrofotômetro (CELM, modelo E-225D, Lauro de Freitas, BA), utilizando-se comprimento de onda de $550 \mathrm{~nm}$.

A separação das frações proteicas foi realizada por eletroforese em gel de agarose, utilizandose tampão Tris $\mathrm{pH} 9,5 \pm 0,2$. As placas de gel de agarose foram coradas em negro de amido a $0,2 \%$ e descoradas em ácido acético a $5 \%$, de acordo com metodologia descrita por FRIEDMAN (1961). Procedeu-se à leitura e ao cálculo do fracionamento eletroforético em densitômetro a $520 \mathrm{~nm}$, segundo CANAVESSI et al. (2000), com separação manual das várias frações proteicas (albumina, alfa, beta e gama globulinas).

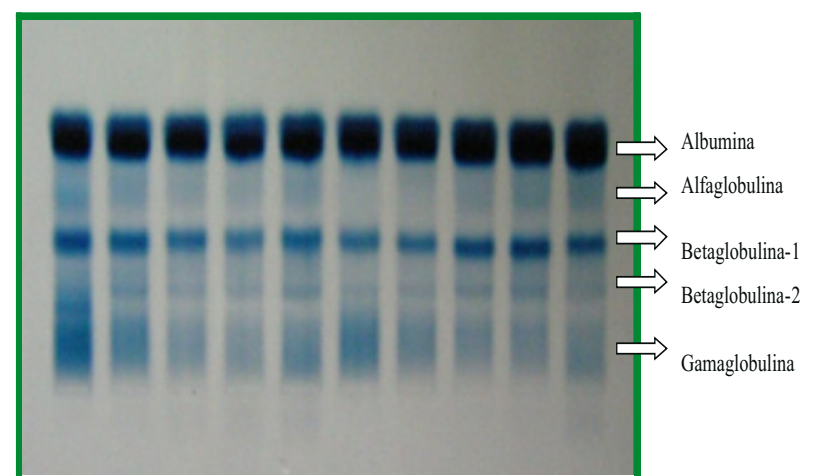

FIGURA 1. Gel de agarose demonstrando o fracionamento eletroforético das proteínas séricas dos cordeiros. Notar a formação de cinco bandas distintas. 
A análise estatística dos dados foi realizada com o auxílio do programa Statistica versão 6.0 (STATISTICA, 2001). Para os dados quantitativos efetuaram-se duas análises com a Prova de Wilcoxon, relacionaramse os dados, para identificação das diferenças significativas entre as médias das variáveis analisadas no proteinograma, entre os momentos, tanto para o grupo monitorado quanto para o grupo não monitorado. Com a Prova de Mann-Whitney, para dados não relacionados, o objetivo foi identificar diferenças significativas entre as médias do grupo monitorado e não monitorado para todas as variáveis analisadas no proteinograma. Todas as análises tiveram como referência $95 \%$ de confiança ( $p<0,05)$, evidenciando um caráter significativo para as comparações efetuadas.

\section{RESULTADOS}

Como pode ser observado na Tabela 1, o valor da proteína sérica total dos cordeiros que constituíam o grupo MO sofreu alterações significativas durante o período experimental. $\mathrm{O}$ menor valor em $\mathrm{g} / \mathrm{dL}$ foi verificado ao nascimento $(3,62 \pm 0,70)$, sofrendo um aumento significativo $(\mathrm{p} \leq 0,05)$ às seis horas $(7,55 \pm$ $3,33)$, atingindo concentração máxima no período de 24-72 horas de vida $(7,98 \pm 1,95)$. Logo em seguida ocorre um decréscimo significativo $(\mathrm{p}<0,05)$ desta concentração até os sete dias de idade $(5,93 \pm 0,61)$ e também até os quinze dias $(4,78 \pm 0,62)$, permanecendo estável até os trinta dias $(4,75 \pm 0,56)$. Após este período, a concentração de proteínas séricas totais volta a sofrer um acréscimo até os sessenta dias $(5,13$ $\pm 0,60)$, chegando aos noventa dias com valor de 6,36 $\pm 0,55$ após sofrer um aumento significativo. Os valores médios da concentração de proteínas séricas totais dos cordeiros do grupo NM se apresentaram de forma semelhante com o desenvolvimento etário: o maior valor foi verificado 24-72 horas após o nascimento $(5,57 \pm 1,45)$, havendo decréscimo gradual até os quinze e trinta dias $(4,92 \pm 0,39)$ e sofrendo acréscimo gradual até os noventa dias $(5,23 \pm 0,44)$, como pode ser observado na Tabela 2.

TABELA 1. Valores médios expressos em g/dL da proteína sérica total (PST) e das frações proteicas separadas eletroforeticamente: albumina (ALB), $\alpha$-globulina $(\alpha), \beta 1$ - globulina $(\beta), \beta 2$-globulina $(\beta), \gamma$-globunina $(\gamma)$ de cordeiros mestiços com aleitamento monitorado (MO) no MA (imediatamente após o nascimento e antes da mamada do colostro), MB (seis horas após o nascimento), M1 (24-72h de vida), M2 (sete dias), M3 (quinze dias), M4 (trinta dias), M5 (sessenta dias), M6 (noventa dias). Santo Amaro da Purificação, BA, 2006

\begin{tabular}{|c|c|c|c|c|c|c|c|c|c|}
\hline "Variáveis & & $\mathrm{MA}, 0 \mathrm{~h}$ & $\mathrm{MB}, 6 \mathrm{~h}$ & M1, 24-72h & M2, 7d & M3, 15d & M4, 30d & M5, 60d & M6, 90d \\
\hline \multirow{2}{*}{$P S T$} & Média & 3,62 & 7,55 & 7,98 & 5,93 & 4,78 & 4,75 & 5,13 & 6,36 \\
\hline & Desvio-padrão & 0,70 & 3,33 & 1,95 & 0,61 & 0,62 & 0,56 & 0,60 & 0,55 \\
\hline \multirow{2}{*}{$A L B$} & Média & 2,05 & 2,78 & 2,71 & 2,24 & 2,05 & 2,21 & 2,31 & 2,85 \\
\hline & Desvio-padrão & 0,46 & 1,00 & 0,38 & 0,34 & 0,35 & 0,33 & 0,45 & 0,33 \\
\hline \multirow{2}{*}{$\alpha$} & Média & 0,26 & 0,39 & 0,41 & 0,37 & 0,39 & 0,38 & 0,41 & 0,53 \\
\hline & Desvio-padrão & 0,14 & 0,31 & 0,16 & 0,09 & 0,15 & 0,08 & 0,11 & 0,14 \\
\hline \multirow{2}{*}{$\beta 1$} & Média & 0,76 & 1,09 & 1,02 & 0,97 & 0,74 & 0,75 & 0,84 & 0,94 \\
\hline & Desvio-padrão & 0,14 & 0,62 & 0,42 & 0,22 & 0,10 & 0,12 & 0,14 & 0,14 \\
\hline \multirow{2}{*}{$\beta 2$} & Média & 0,23 & 0,41 & 0,46 & 0,39 & 0,49 & 0,39 & 0,45 & 0,60 \\
\hline & Desvio-padrão & 0,12 & 0,27 & 0,29 & 0,20 & 0,20 & 0,09 & 0,09 & 0,14 \\
\hline \multirow{2}{*}{$\gamma$} & Média & 0,32 & 2,88 & 3,39 & 1,95 & 1,12 & 1,02 & 1,12 & 1,44 \\
\hline & Desvio-padrão & 0,12 & 1,55 & 1,13 & 0,49 & 0,28 & 0,23 & 0,15 & 0,25 \\
\hline
\end{tabular}

* = Diferenças entre os momentos para cada variável pela prova de Wilcoxon a $5 \%$ de significância:

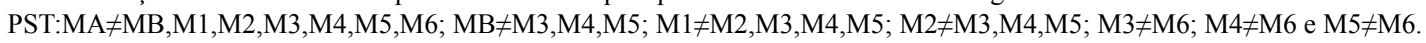

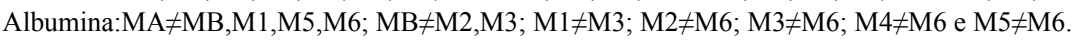

$\alpha$-globulina:MA $\neq \mathrm{M} 4, \mathrm{M} 6 ; \mathrm{M} 1 \neq \mathrm{M} 6 ; \mathrm{M} 2 \neq \mathrm{M} 6 ; \mathrm{M} 4 \neq \mathrm{M} 6$ e $\mathrm{M} 5 \neq \mathrm{M} 6$.

$\beta 1$-globulina:MA $\neq \mathrm{MB}, \mathrm{M} 2, \mathrm{M} 5, \mathrm{M} 6 ; \mathrm{MB} \neq \mathrm{M} 3, \mathrm{M} 4 ; \mathrm{M} 2 \neq \mathrm{M} 3, \mathrm{M} 4, \mathrm{M} 5 ; \mathrm{M} 3 \neq \mathrm{M} 5, \mathrm{M} 6 ; \mathrm{M} 4 \neq \mathrm{M} 5, \mathrm{M} 6$.

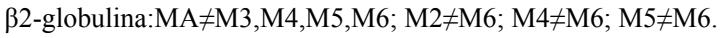

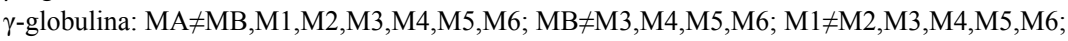

$\mathrm{M} 2 \neq \mathrm{M} 3, \mathrm{M} 4, \mathrm{M} 5, \mathrm{M} 6 ; \mathrm{M} 4 \neq \mathrm{M} 6$ e M5キM6. 
Os valores obtidos para as concentrações da albumina sérica $(\mathrm{g} / \mathrm{dL})$ dos cordeiros cujo fornecimento de colostro foi monitorado demonstraram variações significativas durante o desenvolvimento etário (Tabela 1). O menor valor foi verificado ao nascimento, mantendo-se inalterado aos quinze dias $(2,05 \pm 0,46$ e 2,05 $\pm 0,35$ respectivamente). Logo após nota-se um aumento significativo desta fração às seis horas de vida $(2,78 \pm 1,0)$, que se mantém estável às $24-72$ horas de vida $(2,71 \pm 0,38)$, sofrendo ainda um pequeno decréscimo aos sete dias $(2,24 \pm 0,34)$ e diminuindo significativamente $(\mathrm{p}<0,05)$ aos quinze dias. Após este período os teores de albumina sérica voltam a sofrer acréscimo gradual, atingindo seu valor máximo aos noventa dias $(2,85 \pm 0,33)$. Similarmente se comportaram as concentrações de albumina sérica dos animais do grupo NM em seus períodos estudados, atingindo valor máximo aos noventa dias $(2,70 \pm 0,37)$.

TABELA 2. Valores médios expressos em g/dL da proteína sérica total (PST) e das frações proteicas separadas eletroforeticamente: albumina (ALB), $\alpha$-globulina $(\alpha)$, $\beta 1$ - globulina $(\beta), \beta 2$-globulina $(\beta), \gamma$-globunina $(\gamma)$ de cordeiros com aleitamento não monitorado (NM) no M1 (24-72h de vida), M2 (sete dias), M3 (quinze dias), M4 (trinta dias), M5 (sessenta dias), M6 (noventa dias). Santo Amaro da Purificação, BA, 2006

\begin{tabular}{|c|c|c|c|c|c|c|c|}
\hline "Variáveis & & $\begin{array}{c}\text { M1 } \\
24-72 h\end{array}$ & $\begin{array}{l}\text { M2 } \\
7 \mathrm{~d}\end{array}$ & $\begin{array}{l}\text { M3 } \\
15 d\end{array}$ & $\begin{array}{l}\text { M4 } \\
30 \mathrm{~d}\end{array}$ & $\begin{array}{l}\text { M5 } \\
60 \mathrm{~d}\end{array}$ & $\begin{array}{l}\text { M6 } \\
90 d\end{array}$ \\
\hline \multirow{2}{*}{$P S T$} & Média & 5,57 & 5,32 & 4,91 & 4,92 & 4,96 & 5,23 \\
\hline & Desvio-padrão & 1,45 & 0,97 & 0,53 & 0,39 & 0,33 & 0,44 \\
\hline \multirow{2}{*}{$A L B$} & Média & 2,46 & 2,58 & 2,42 & 2,56 & 2,58 & 2,70 \\
\hline & Desvio-padrão & 0,58 & 0,52 & 0,41 & 0,46 & 0,41 & 0,37 \\
\hline \multirow{2}{*}{$\alpha$} & Média & 0,29 & 0,33 & 0,39 & 0,40 & 0,39 & 0,37 \\
\hline & Desvio-padrão & 0,17 & 0,11 & 0,11 & 0,10 & 0,10 & 0,10 \\
\hline \multirow{2}{*}{$\beta 1$} & Média & 0,72 & 0,72 & 0,75 & 0,76 & 0,70 & 0,70 \\
\hline & Desvio-padrão & 0,24 & 0,15 & 0,12 & 0,14 & 0,12 & 0,17 \\
\hline \multirow{2}{*}{$\beta 2$} & Média & 0,31 & 0,41 & 0,38 & 0,40 & 0,40 & 0,39 \\
\hline & Desvio-padrão & 0,16 & 0,18 & 0,13 & 0,14 & 0,11 & 0,16 \\
\hline \multirow[b]{2}{*}{$\gamma$} & Média & 1,80 & 1,28 & 0,97 & 0,80 & 0,90 & 1,05 \\
\hline & Desvio-padrão & 0,95 & 0,53 & 0,38 & 0,25 & 0,25 & 0,30 \\
\hline
\end{tabular}

* = Diferenças entre os momentos para cada variável pela prova de Wilcoxon a $5 \%$ de significância:

PST: $\mathrm{M} 1 \neq \mathrm{M} 3, \mathrm{M} 4, \mathrm{M} 5 ; \mathrm{M} 2 \neq \mathrm{M} 3, \mathrm{M} 4 ; \mathrm{M} 3 \neq \mathrm{M} 6 ; \mathrm{M} 4 \neq \mathrm{M} 6$ e $\mathrm{M} 5 \neq \mathrm{M} 6$.

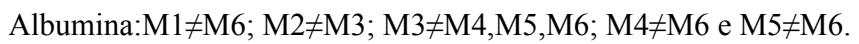

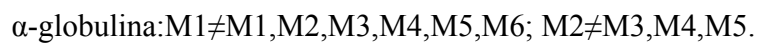

$\beta 1$-globulina:M3 $\neq \mathrm{M} 5$

$\beta 2$-globulina:M1 $\neq \mathrm{M} 2, \mathrm{M} 3, \mathrm{M} 4, \mathrm{M} 5, \mathrm{M} 6$

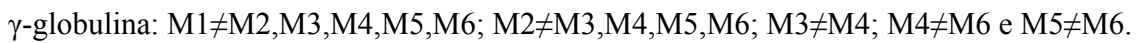

Os valores obtidos para as concentrações da fração alfaglobulina $(\mathrm{g} / \mathrm{dL})$ do soro sanguíneo dos cordeiros do grupo MO não sofreram muitas diferenças no decorrer do período experimental (Tabela 1). Ao nascimento, apresentou valor de $0,26 \pm 0,14$, mantendo-se estável até os trinta dias de idade, quando sofreu significativo aumento $(0,38 \pm 0,08)$. Após este período, mantém-se estável aos sessenta dias de idade, sofrendo um aumento significativo $(\mathrm{p}<0,05)$ aos noventa dias, atingindo sua maior concentração $(0,53 \pm 0,14)$. No grupo NM, as concentrações de alfaglobulinas médias não sofreram grandes variações com o desenvolvimento etário (Tabela 2). Seu menor valor foi observado às 24-72 horas após o nascimento, sofrendo acréscimo aos sete e aos quinze dias de idade, quando se estabilizaram até os noventa dias. 
O traçado eletroforético das proteínas séricas dos cordeiros permitiu visualizar duas bandas da fração betaglobulina, a $\beta 1$-globulina (mais rápida) e a $\beta 2$-globulina (mais lenta). Os valores séricos médios obtidos para a concentração da $\beta 1$-globulina $(\mathrm{g} / \mathrm{dL})$ sofreram variações significativas com o desenvolvimento etário nos cordeiros do grupo MO (Tabela 1). Ao nascimento a sua concentração era de $0,76 \pm 0,14$ e sofreu um acréscimo significativo às seis horas após o nascimento $(1,09 \pm 0,62)$. Após isso, se manteve estável até os sete dias de idade. No entanto, sofreu decréscimo significativo aos quinze dias $(0,74 \pm 0,10)$, mantendo-se estável novamente até sessenta dias de idade. Após isto, sofreu um acréscimo significativo aos noventa dias $(0,94 \pm 0,14)$. A fração $\beta 1$-globulina do soro dos cordeiros do grupo NM não sofreu alterações significativas com o desenvolvimento etário (Tabela 2). A evolução das suas concentrações foi bem similar ao comportamento desta mesma fração no soro dos animais do grupo MO.

Os valores séricos médios obtidos para a concentração da $\beta 2$-globulina (g/dL) em cordeiros do grupo MO sofreram poucas variações significativas com o desenvolvimento etário (Tabela 1). Manteve-se estável do nascimento até os sete dias, sofrendo um discreto, porém não significativo, aumento às seis horas de vida $(0,23 \pm 0,12$ e $0,41 \pm 0,27$ respectivamente). Aos quinze dias apresentou aumento significativo $(0,49$ $\pm 0,20)$, mantendo-se estável até os sessenta dias e sofrendo um novo aumento aos noventa dias de idade $(0,60 \pm 0,14)$. A referida fração proteica no soro dos cordeiros do grupo NM evoluiu de forma semelhante do nascimento aos noventa dias (Tabela 2).

Os valores médios obtidos para a concentração da gamaglobulina sérica ( $\mathrm{g} / \mathrm{dL}$ ) nos cordeiros cujo fornecimento de colostro foi monitorado (MO) sofreram modificações significativas durante o desenvolvimento etário (Tabela 1). Ao nascimento, foi obtido o valor mínimo de todo o período experimental $(0,32 \pm 0,12)$. Seis horas após o nascimento, os valores sofreram um significativo aumento para teores de 2,88 $\pm 1,55$; atingindo valores ainda maiores no período de $24-72 \mathrm{~h}$ de vida $(3,39 \pm 1,13)$. Esta concentração vai sofrendo decréscimo gradativo $(\mathrm{p}<0,05)$ até trinta dias de idade, quando atinge seus menores teores $(1,02 \pm 0,23)$. Estas concentrações voltam a sofrer aumento gradual até os noventa dias, atingindo teores de $(1,44 \pm 0,25)$. No grupo de cordeiros NM, as concentrações médias da fração gamaglobulina se comportaram da mesma forma (Tabela 2), apresentando valor máximo nas 24-72 horas de vida $(1,80 \pm 0,95)$, sofrendo decréscimo até os trinta dias de idade, quando apresenta o valor mínimo $(0,80$ $\pm 0,25)$ e após este período volta a sofrer acréscimo até os noventa dias de idade $(1,05 \pm 0,30)$.

Os valores do proteinograma dos cordeiros dos grupos MO e NM estão apresentados na Tabela 3. Os teores séricos de proteína total dos cordeiros submetidos ao manejo de monitoramento da primeira mamada do colostro (MO) foram significativamente superiores $(\mathrm{p}<0,05)$ aos dos cordeiros cuja mamada do colostro se deu de forma natural (NM) no M1 (7,98 $\pm 1,95 \mathrm{~g} / \mathrm{dL}$ e $5,57 \pm 1,45 \mathrm{~g} / \mathrm{dL}$ para $\mathrm{MO}$ e NM respectivamente) e no M6 $(6,36 \pm 0,55 \mathrm{~g} / \mathrm{dL}$ e $5,23 \pm 0,44 \mathrm{~g} / \mathrm{dL}$ para MO e NM respectivamente). Estas concentrações também diferiram entre si no momento de apresentação do valor mínimo $(4,75 \pm 0,56 \mathrm{~g} / \mathrm{dL}$ no M4 e 4,91 $\pm 0,53 \mathrm{~g} /$ dL no M3 para os grupos MO e NM, respectivamente). Também apresentaram diferenças significativas entre os grupos experimentais (MO e NM) no M1 os teores de gamaglobulinas. As concentrações desta fração globulina apresentaram diferenças significativas entre os grupos em todos os momentos do experimento até o desmame (noventa dias). Os teores séricos de albumina foram maiores no grupo MO nos M1 e M6. Nos M2, M3 e M4 estes teores foram significativamente superiores no grupo NM em relação ao grupo MO.

As concentrações da fração alfaglobulina não apresentaram diferenças significativas entre os diferentes manejos de fornecimento de colostro durante os momentos experimentais, com exceção do M6, quando o grupo MO apresentou valores maiores do que o grupo $\mathrm{NM}(0,53 \pm 0,14 \mathrm{~g} / \mathrm{dL}$ e $0,37 \pm 0,10 \mathrm{~g} / \mathrm{dL}$ respectivamente). As concentrações da fração $\beta 1$-globulina foram maiores no grupo $\mathrm{MO}$ em relação ao grupo NM nos momentos M2 e M6. Já a fração $\beta 2$-globulina se apresentou com concentrações maiores em MO somente aos noventa dias de idade (Tabela 3 ).

Aos noventa dias de idade, notou-se uma maior concentração sérica de todos os componentes proteicos dos cordeiros de $\mathrm{MO}$ em relação aos cordeiros de NM, com significância estatística ( $\mathrm{p}<0,05)$, excetuando-se a fração albumina, que também se apresentou superior em MO, porém sem significância. 
TABELA 3. Valores médios expressos em $\mathrm{g} / \mathrm{dL}$ da proteína sérica total (PST) e das frações proteicas separadas eletroforeticamente: albumina (ALB), $\alpha$-globulina ( $\alpha$ ), $\beta 1$ - globulina ( $\beta$ ), $\beta 2$-globulina $(\beta), \gamma$-globunina $(\gamma)$ de cordeiros com aleitamento monitorado (MO) e não-monitorado (NM) no M1 (24-72h de vida), M2 (sete dias), M3 (quinze dias), M4 (trinta dias), M5 (sessenta dias), M6 (noventa dias). Santo Amaro da Purificação, BA, 2006

\begin{tabular}{|c|c|c|c|c|c|c|c|}
\hline & Grupos & $\begin{array}{c}\text { M1 } \\
(24-72 h)\end{array}$ & $\begin{array}{l}\text { M2 } \\
(7 d)\end{array}$ & $\begin{array}{c}\text { M3 } \\
(15 \mathrm{~d})\end{array}$ & $\begin{array}{c}\text { M4 } \\
(30 d)\end{array}$ & $\begin{array}{c}\text { M5 } \\
(60 d)\end{array}$ & $\begin{array}{c}\text { M6 } \\
(90 d)\end{array}$ \\
\hline \multirow{2}{*}{$P S T$} & $M O$ & $7,98 \pm 1,95 \mathrm{~A}^{*}$ & $5,93 \pm 0,61 \mathrm{~A}$ & $4,78 \pm 0,62 \mathrm{~A}$ & $4,75 \pm 0,56 \mathrm{~A}$ & $5,13 \pm 0,60 \mathrm{~A}$ & $6,36 \pm 0,55 \mathrm{~A}$ \\
\hline & $N M$ & $5,57 \pm 1,45 \mathrm{~B}$ & $5,32 \pm 0,97 \mathrm{~A}$ & $4,91 \pm 0,53 \mathrm{~A}$ & $4,92 \pm 0,39 \mathrm{~A}$ & $4,96 \pm 0,33 \mathrm{~A}$ & $5,23 \pm 0,44 \mathrm{~B}$ \\
\hline \multirow{2}{*}{$A L B$} & $M O$ & $2,71 \pm 0,38 \mathrm{~A}$ & $2,24 \pm 0,34 \mathrm{~A}$ & $2,05 \pm 0,35 \mathrm{~A}$ & $2,21 \pm 0,33 \mathrm{~A}$ & $2,31 \pm 0,45 \mathrm{~A}$ & $2,85 \pm 0,33 \mathrm{~A}$ \\
\hline & $N M$ & $2,46 \pm 0,58 \mathrm{~A}$ & $2,58 \pm 0,52 \mathrm{~B}$ & $2,42 \pm 0,41 \mathrm{~B}$ & $2,56 \pm 0,46 \mathrm{~B}$ & $2,58 \pm 0,41 \mathrm{~A}$ & $2,70 \pm 0,37 \mathrm{~A}$ \\
\hline \multirow{2}{*}{$\alpha$} & $M O$ & $0,41 \pm 0,16 \mathrm{~A}$ & $0,37 \pm 0,09 \mathrm{~A}$ & $0,39 \pm 0,15 \mathrm{~A}$ & $0,38 \pm 0,08 \mathrm{~A}$ & $0,41 \pm 0,11 \mathrm{~A}$ & $0,53 \pm 0,14 \mathrm{~A}$ \\
\hline & $N M$ & $0,29 \pm 0,17 \mathrm{~A}$ & $0,33 \pm 0,11 \mathrm{~A}$ & $0,39 \pm 0,11 \mathrm{~A}$ & $0,40 \pm 0,10 \mathrm{~A}$ & $0,39 \pm 0,10 \mathrm{~A}$ & $0,37 \pm 0,10 \mathrm{~B}$ \\
\hline \multirow{2}{*}{$\beta 1$} & $M O$ & $1,02 \pm 0,42 \mathrm{~A}$ & $0,97 \pm 0,22 \mathrm{~A}$ & $0,74 \pm 0,10 \mathrm{~A}$ & $0,75 \pm 0,12 \mathrm{~A}$ & $0,84 \pm 0,14 \mathrm{~A}$ & $0,94 \pm 0,14 \mathrm{~A}$ \\
\hline & $N M$ & $0,72 \pm 0,24 \mathrm{~A}$ & $0,72 \pm 0,15 \mathrm{~B}$ & $0,75 \pm 0,12 \mathrm{~A}$ & $0,76 \pm 0,14 \mathrm{~A}$ & $0,70 \pm 0,12 \mathrm{~B}$ & $0,70 \pm 0,17 \mathrm{~B}$ \\
\hline \multirow{2}{*}{$\beta 2$} & $M O$ & $0,46 \pm 0,29 \mathrm{~A}$ & $0,39 \pm 0,20 \mathrm{~A}$ & $0,49 \pm 0,20 \mathrm{~A}$ & $0,39 \pm 0,09 \mathrm{~A}$ & $0,45 \pm 0,09 \mathrm{~A}$ & $0,60 \pm 0,14 \mathrm{~A}$ \\
\hline & $N M$ & $0,31 \pm 0,16 \mathrm{~A}$ & $0,41 \pm 0,18 \mathrm{~A}$ & $0,38 \pm 0,13 \mathrm{~A}$ & $0,40 \pm 0,14 \mathrm{~A}$ & $0,40 \pm 0,11 \mathrm{~A}$ & $0,39 \pm 0,16 \mathrm{~B}$ \\
\hline \multirow[b]{2}{*}{$\gamma$} & $M O$ & $3,39 \pm 1,13 \mathrm{~A}$ & $1,95 \pm 0,49 \mathrm{~A}$ & $1,12 \pm 0,28 \mathrm{~A}$ & $1,02 \pm 0,23 \mathrm{~A}$ & $1,12 \pm 0,15 \mathrm{~A}$ & $1,44 \pm 0,25 \mathrm{~A}$ \\
\hline & $N M$ & $1,80 \pm 0,95 \mathrm{~B}$ & $1,28 \pm 0,53 \mathrm{~B}$ & $0,97 \pm 0,38 \mathrm{~A}$ & $0,80 \pm 0,25 \mathrm{~B}$ & $0,90 \pm 0,25 \mathrm{~B}$ & $1,05 \pm 0,30 \mathrm{~B}$ \\
\hline
\end{tabular}

*Letras iguais na mesma coluna, em cada variável, não diferem entre si pela prova de pela Prova de Mann-Whitney a 5\% de significância.

\section{DISCUSSÃO}

A ingestão e absorção de adequadas quantidades de colostro de boa qualidade são essenciais para a sobrevivência dos ruminantes jovens. As mamadas precoces naturais ou forçadas de colostro comprovadas durante as primeiras seis horas de vida ajudam a assegurar uma transferência adequada de anticorpos maternais (CHRISTLEY et al., 2003). Em rebanhos ovinos especialmente, em que há elevadas taxas de mortalidade neonatal associadas a infecções, é preciso determinar e monitorar a transferência passiva da imunidade. Em alguns casos deve-se instituir a alimentação forçada do colostro, como foi proposto nesta pesquisa.

Neste estudo, as modificações observadas nas concentrações de proteína total durante desenvolvimento etário foram, basicamente, consequência das frações de albumina e de gamaglobulina. Isto está de acordo com as observações de WEAVER (2000) e FAGLIARI et al. (1986). Após o nascimento e antes da ingestão de colostro, as proteínas se apresentam com valores baixos, em virtude dos teores mínimos de globulinas e baixos teores de albumina. No entanto, após a ingestão de colostro, há um rápido aumento da fração gamaglobulina, como resultado da absorção das imunoglobulinas colostrais.

Dada a escassez de trabalhos realizados para aferir as concentrações de proteína total do soro de cordeiros, foi necessário extrapolar as comparações com valores obtidos para outros ruminantes jovens. Assim sendo, os resultados para a concentração de proteínas totais também foram semelhantes aos observados por FEITOSA et al. (2001a), em quarenta bezerros da raça holandesa, cuja concentração de proteínas totais no grupo de animais foi de $7,02 \pm 0,96 \mathrm{~g} / \mathrm{dL}$ às 24 horas do nascimento. 
A concentração de proteínas totais e frações eletroforéticas no soro de cordeiros obtidas neste estudo foram semelhantes aos determinados em neonatos ruminantes por outros autores em bezerros (FEITOSA et al., 1999, 2001b; COSTA, 2004), cabritos (CHENA et al., 1999; SIMÕES et al., 2005) e em bubalinos (SILVA et al., 1993). Porém existem algumas diferenças no momento de pico destas concentrações bem como nos valores destas. Isso se deve principalmente às diferenças entre espécies e metodologias. As concentrações de proteína total às 24-72 horas após o nascimento também estão de acordo com os achados de BEKELE et al. (1992), que obtiveram teores médios de 8,39 \pm $0,62 \mathrm{~g} / \mathrm{dL}$ às 48 horas de vida.

Um comportamento semelhante das concentrações de proteína total e da fração globulina foi descrito por SILVA et al. (1993), analisando proteinograma de bubalinos recém-nascidos. Estes notaram uma diminuição da concentração de anticorpos após as 24 horas do nascimento, o que pode ser devido ao bloqueio intestinal para a absorção de macromoléculas do colostro, assim como ocorre em bezerros.

Os teores de proteína sérica total variaram de acordo com o desenvolvimento etário tanto no grupo MO quanto no grupo NM. O resultado está de acordo com o comportamento da proteína sérica total observado por outros autores em pesquisas com ruminantes jovens, em que após o pico (cerca de um a dois dias de idade), há o declínio, em virtude do catabolismo dos anticorpos adquiridos passivamente, aproximadamente aos trinta dias de idade, e a estabilização refletindo o comportamento das imunoglobulinas (DANIELE et al., 1994; FEITOSA et al., 1999; FEITOSA et al., 2001b; PAULETTI et al., 2002; LEAL et al., 2003; COSTA, 2004).

O ponto de concentração mínima das proteínas totais equivale à fase de transição entre o catabolismo das imunoglobulinas exógenas e o início da produção endógena da IgG e outras classes de imunoglobulinas. No presente trabalho, este ponto foi observado aos quinze e trinta dias em ambos os grupos experimentais, sendo similar às observações de PAULETTI et al. (2002).

$\mathrm{O}$ aleitamento artificial tem como vantagens o controle da quantidade de leite ingerido e menor ocorrência de diarreias. E, como desvantagens, tem a necessidade de mão de obra e de melhores instalações, a higiene dos vasilhames, o controle da temperatura e o adequado armazenamento do leite (MACHADO NETO et al., 2004a). O fornecimento de colostro com monitoramento e suplementação às doze horas após o nascimento teve efeitos positivos, elevando a proteinemia e diminuindo a mortalidade de ruminantes jovens nos trabalhos de MACHADO NETO (2004a,b). SIMÕES et al. (2005) também concluíram que o fornecimento de duas parcelas de $200 \mathrm{~mL}$ de colostro (imediatamente após o nascimento e oito horas após o parto) assegura uma maior proteinemia e gamaglobulinemia aos cabritos, conferindo-lhes bons níveis de imunidade passiva. O contrário foi verificado por FEITOSA et al. (1999 e 2003), que definiram que a mamada natural do colostro forneceu maiores concentrações de proteínas totais e gamaglobulinas ou boa transferência de imunidade passiva.

Neste trabalho, a proteinemia do grupo de ingestão de colostro monitorada foi superior, às 24-72 horas, em relação ao grupo não monitorado. BORGES et al. (2001) constataram proteinemia menor em bezerros que mamaram em suas próprias mães. Já RIZZOLI et al. (2006) observaram proteinemia maior em bezerros que mamaram o colostro nas próprias vacas, de forma natural, do que naqueles que o receberam em mamadeira até os trinta dias de idade, verificando também o mesmo comportamento na fração gamaglobulina neste período.

No presente trabalho, a fração albumina do soro dos cordeiros apresentou poucas variações no decorrer do tempo. Sofreu um acréscimo após a ingestão do colostro e pequenas oscilações até os noventa dias, quando apresentou o seu maior valor. Estes resultados estão de acordo com FEITOSA (2001b) e COSTA (2004), que obtiveram valores mínimos ao nascimento e aumento gradual durante o desenvolvimento etário (150 dias). No entanto, os resultados estão discordantes dos observados por DANIELE et al. (1994), que não verificaram variação da concentração de albumina sérica ao longo do seu período experimental. $\mathrm{O}$ aumento da albumina se deve ao aumento da ingestão de compostos nitrogenados na dieta. Isto está de acordo com as observações deste trabalho, uma vez que os cordeiros já apresentavam ruminação e aproveitamento de componentes nitrogenados a partir dos trinta dias de idade.

Os valores obtidos para as concentrações da fração alfaglobulina (g/dL) do soro sanguíneo dos 
cordeiros do grupo MO e NM não sofreram muitas diferenças no decorrer do período experimental. Este comportamento em relação ao tempo está de acordo com as observações de FEITOSA et al. (2001b), LEAL et al. (2003) e COSTA (2004). Este último pesquisador relata em seu trabalho que, em bezerras sadias, existe uma estabilidade de alfaglobulinas séricas, uma vez que seus teores são mantidos durante os primeiros trinta dias de idade.

As variações observadas na fração alfaglobulina e betaglobulina ao longo do experimento e suas diferenças entre os grupos são de difícil interpretação, em virtude dos seus variados componentes e de sua possibilidade de variação em condições fisiológicas e nas enfermidades (SIMÕES et al., 2005).

Ao confrontar os valores médios da concentração de betaglobulinas no soro de cordeiros de ambos os grupos com outros pesquisadores que os determinaram em ruminantes jovens em diferentes idades, verificou-se concordância com o perfil de variação observado por FEITOSA et al. (2001b), LEAL et al. (2003) e RIZZOLI et al. (2006). A maioria dos pesquisadores constatou que as betaglobulinas atingem um valor de concentração sérica elevado após a ingestão de colostro, sofrendo discretas oscilações com o desenvolvimento etário, fato observado neste trabalho. Isso prova a migração de algumas imunoglobulinas também nesta fração betaglobulina. BORGES et al. (2001) verificaram também variação significativa da concentração de betaglobulinas em decorrência da ingestão de colostro em bezerros.

Os valores médios obtidos para a concentração de gamaglobulina $(\mathrm{g} / \mathrm{dL})$ nos cordeiros dos grupos experimentais deste trabalho sofreram modificações significativas durante o desenvolvimento etário e também sofreram influência da forma de fornecimento do colostro. É importante ressaltar que a concentração desta fração era mínima ao nascimento no grupo MO $(0,32 \pm 0,12)$ e apresentou valores máximos 24-72 horas após o nascimento para ambos os grupos $(3,39$ $\pm 1,13$ e $1,80 \pm 0,95$ para o grupo MO e NM respectivamente). Após este período, em ambos os grupos, os teores de gamaglobulinas sofreram decréscimo até os quinze a trinta dias e a partir daí voltaram a crescer até os noventa dias. Estas modificações com o desenvolvimento etário estão de acordo com as observações de outros autores em neonatos ruminantes (MORAES et al., 1997; BORGES et al., 2001; FEITOSA et al., 2001b; LEAL et al., 2003; COSTA, 2004; SIMÕES et al., 2005; RIZZOLI et al., 2006; REIS, 2007).

A diminuição significativa dos teores de gamaglobulina observados aos 15-trinta dias de idade provavelmente ocorreu em virtude do consumo ou da degradação das imunoglobulinas transferidas passivamente pela ingestão do colostro. $\mathrm{O}$ aumento significativo dos teores de gamaglobulina verificados a partir deste período decorreu provavelmente de uma resposta aos estímulos causados pela exposição aos diversos tipos de antígenos, aos quais estes animais estão constantemente expostos, demonstrando a reatividade do sistema imunológico do neonato ruminante (CORPA et al., 2000).

Diante disso, pode-se observar que as frações proteicas, em sua maioria, sofrem variações com o desenvolvimento etário, em especial as proteínas séricas totais, albumina, betaglobulina e gamaglobulina. Os fatores determinantes para estas variações são a ingestão do colostro após o nascimento, o consumo e degradação das imunoglobulinas até os trinta dias de idade, a produção endógena ativa das imunoglobulinas diante dos desafios do ambiente e a ingestão de compostos nitrogenados.

\section{CONCLUSÕES}

Conclui-se que o monitoramento da mamada do colostro é uma medida simples de ser adotada nos sistemas de manejo e pode elevar significativamente os teores de proteínas séricas, betaglobulinas e especialmente gamaglobulinas. Esta medida pode minimizar as falhas de transferência passiva de anticorpos e refletir em redução de morbidade e mortalidade e também em aumento de produtividade em rebanhos ovinos.

\section{AGRADECIMENTOS}

Ao Sr. André Teixeira, pela cessão da propriedade e dos animais, à CAPES, pela bolsa de estudos concedida.

\section{REFERÊNCIAS}

ARGUEllo, A.; CASTRO, N.; ZAMORANO, M. J.; CASTROALONSO, A.; CAPOTE, J. Passive transfer of immunity in 
kid goats fed refrigerated and frozen goat colostrums and commercial sheep colostrums. Small Ruminant Research, n. 54, p. 237-241, 2004.

BEKELE, T.; OTESILE, E. B.; KASALI, O. B. Influence of passively acquired colostral immunity on neonatal lamb mortality in Ethiopian highland sheep. Small Ruminant Research, n. 9, p. 209-215, 1992.

BORGES, A. S.; FEITOSA, F. L. F.; BENESI, F. J.; BIRGEL, E. H.; MENDES, L. C. N. Influência da forma de administração e da quantidade fornecida de colostro sobre a concentração de proteína total e de suas frações eletroforéticas no soro sanguíneo de bezerros da raça Holandesa. Arquivo Brasileiro de Medicina Veterinária e Zootecnia, v. 53, n. 5, p. 629-634, 2001.

CANAVESSI, A. M. O.; CHIACCHIO, S. B.; SARTORI, R.; CURI, P. R. Valores do perfil eletroforético das proteínas séricas de bovinos da raça nelore (Bos indicus) criados na região de Botucatu, São Paulo: influência dos fatores etários e sexuais. Arquivos do Instituto Biológico, v. 67, p. 9-17, 2000.

CHENA, J. C.; CHANG, C. J; PEHA, H. C.; CHENB, S. Y. Serum protein levels and neonatal growth rate of Nubian goat kids in Taiwan area. Small Ruminant Research, v. 32, p. 153-160, 1999.

CHRISTLEY, R. M.; MORGAN, D. L.; PARKIN, T. D. H.; FRENCH, N. P. Factors related to the risk of neonatal mortality, birthwheight and serum immunoglobulin concentration in lambs in the UK. Preventive Veterinary Medicine, v. 57, p. 209-226, 2003.

CONSTANT, B. S.; LEBLANC, M. M.; KLAPSTEIN, E. F.; BEEBE, D. E.; LENEAU, H. M.; NUNIER, C. J. Serum immunoglobulin $\mathrm{G}$ concentration in goat kids fed colostrum or a colostrum substitute. Journal of the American Veterinary Medical Association, v. 205, n. 12, p. 1759-1762, 1994.

CORPA, J. M.; PEREZ, V.; GARCIA MARIN, J. Differences in the immune responses in lambs and kids vaccinated against paratuberculosis, according to the age of vaccination. Veterinary Microbiology, v. 77, n. 3-4, p. 2731-2736, 2000.

COSTA, J. N.; PEIXOTO, A. P. C.; KOHAYAGAWA, A.; FERREIRA, A. F. M. S. C.; CASSETARI, M. L.; CROCCI, A. J. Influência do desenvolvimento etário e da suplementação com vitamina $\mathrm{E}$ (acetato de dl alfatocoferol) no metabolismo oxidativo dos neutrófilos de bovinos da raça holandesa (Bos taurus). Brazilian Journal of Veterinary Research and Animal Science, v. 41, n. 5, p. 293-298, 2004.

DANIELE, C.; MACHADO NETO, R.; BARACAT, R. S.; BESSI, R. Efeito de diferentes manejos de fornecimento prolongado de colostro sobre os níveis de proteína e albumina séricas e desempenho de bezerras recém-nascidas. Scientia Agricola, v. 51, n. 2 , p. 381-388, 1994.
DOBBELAAR, P.; NOORDHUIZEN, J. P. T. M; VAN KEULEN, K. A. S. An epidemiological study of gammaglobulin levels in newborn calves. Preventive Veterinary Medicine, v. 5, p. 5162,1987

FAGLIARI, J. J.; LUCAS, A; OLIVEIRA, J. A.; FERREIRA NETO, J. M. Quadro seroproteico de bezerros submetidos a três sistemas de imunização contra paratifo. Arquivo Brasileiro de Medicina Veterinária e Zootecnia, v. 38, p. 665-683, 1986.

FEITOSA, F. L. F.; BIRGEL, E. H.; MENDES, L. C. M.; PERRI, S. H. V. Relação entre a concentração de imunoglobulinas colostrais e a transferência de imunidade passiva para bezerros da raça Holandesa após ingestão voluntária de colostro. Ciência Veterinária nos Trópicos, v. 2, n. 3, p. 160-168, 1999.

FEITOSA, F. L. F; BIRGEL, E. H.; MIRANDOLA, R. M. S.; PERRI, S. H. V. Diagnóstico de falha de transferência de imunidade passiva em bezerros através da determinação de proteína total e de suas frações eletrofroréticas, imunoglobulinas $\mathrm{G}$ e $\mathrm{M}$ e da atividade da gama glutamil transferase no soro sanguíneo. Ciência Rural, v. 31 , n. 2, p. 251-255, 2001 a.

FEITOSA, F. L. F.; BIRGEL, E. H.; MIRANDOLA, R. M. S.; PERRI, S. H. V. Proteinograma sérico de bezerros holandeses do nascimento até um ano de vida. Revista Brasileira de Ciência Veterinária, v. 8, n. 2, p. 105-108, 2001 b.

FEITOSA, F. L. F; BORGES, A. S.; BENESI, F. J.; BIRGEL, E. H.; MENDES, L. C. N.; PEIRO, J. R. Concentração de imunoglobulinas $\mathrm{G}$ e $\mathrm{M}$ no soro sanguíneo de bezerros da raça Holandesa até os noventa dias de idade. Brazilian Journal of Veterinary Research and Animal Science, v. 40, suppl. 1, p. 26-31, 2003.

FONTES, F. A. P. V.; COELHO, S. G.; COSTA, T. C. Efeitos da nutrição no sistema imune e na resistência a doenças. Revista Técnica da Bovinocultura de Leite, Caderno especial, 1. ed. mar. 2007. 30 p.

FRIEDMAN, H. S. A standardized procedure for serum protein electrophoresis on cellulose acetate membrane strips. Clinica Chimica Acta, v. 6, p. 775-781, 1961.

KEAY, G.; DOXEY, D. L. Species characteristics of serum proteins demonstrated after agarose gel. Veterinary Research Communications, n. 1, v. 5, p. 263-270, 1982.

LEAL, M .L. R.; BENESI, F. J.; LISBÔA, J. A. N.; COELHO, C. S.; MIRANDOLA, R. M. S. Proteinograma sérico de bezerras sadias, da raça holandesa, no primeiro mês pós-nascimento. Brazilian Journal of Veterinary Research and Animal Science, $\mathrm{n}$. 2, v. 40, p. 138-145, 2003.

MACHADO NETO, R.; FARONI, C. E.; PAULETTI, P.; BESSI, R. Levantamento do manejo de bovinos leiteiros recém-nascidos: 
desempenho e aquisição de proteção passiva. Revista Brasileira

de Zootecnia, v. 33, n. 6, suppl. 3, p. 2323-2329, 2004a.

MACHADO NETO, R.; CASSOLI, L. D.; BESSI, R.; PAULETTI, P. Avaliação do fornecimento adicional de colostro para bezerros. Revista Brasileira de Zootecnia, v. 33, n. 2, p. 420-425, 2004 b.

MORAES, M. P.; WEIBLEN, R.; SILVA, A. M.; TOBIAS, F. L. Evolução da imunidade passiva em fêmeas bovinas da raça holandesa. Ciência Rural, v. 27, n. 3, p. 435-440, 1997.

PAULETTI, P.; MACHADO NETO, R.; PACKER, I. U.; BESSI, R. Avaliação de níveis séricos de imunoglobulina, proteína e o desempenho de bezerras da raça holandesa. Pesquisa Agropecuária Brasileira, v. 37, n. 1, p. 89-94, 2002.

REIS, M. C.; COSTA, J. N.; PEIXOTO, A. P. C. Efeito da idade e da suplementação oral com o acetato de DL-alfa-tocoferol sobre os níveis séricos de vitamina $\mathrm{E}$ e sobre o proteinograma de bezerro. Revista Brasileira de Saúde e Produção Animal, v. 8, n. 3, p. 152-161, 2007.

RIZZOLI, F. W.; FAGLIARI, J. J; SILVA, D. G; JORGE, R. R. L. Proteinograma e teores séricos de cálcio, fósforo, magnésio e ferro de bezerros recém-nascidos que mamaram colostro diretamente na vaca ou em mamadeira. ARS Veterinária, v. 22, p. 10-17, 2006.

SANTAROSA, K. T.; ROCHA E SILVA, R. C.; SILVA, J. B. A.; SOTO-BLANCO, B. Valores de referência para o perfil eletroforético de proteínas séricas em cabras. Archives of Veterinary Science, v. 10, n. 3, p. 46-48, 2005.

SILVA, M. C.; QUEIROZ, W. T.; LAU, H. D.; VALE, W. G. Colostrum and serum protein levels in water buffaloes. Pesquisa Agropecuária Brasileira, v. 28, n. 6, p. 751-757, 1993.

SIMÕES, S. V. D; COSTA, R. G., SOUZA, P. M.; MEDEIROS, A. N.; VILAR, A. L. T. Imunidade passiva, morbidade neonatal e desempenho de cabritos em diferentes manejos de colostro. Pesquisa Veterinária Brasileira, v. 25, n. 4, p. 219-224, 2005.

STATISTICA version 6.0. Data analysis software system. Tulsa: StatSoft Inc., 2001. Disponível em: <www.statsoft.com>.

WEAVER, D. M. Passive transfer of colostral immunoglobulins in calves. Journal of Veterinary Internal Medicine, v. 14, n. 6, p. $569-677,2000$.

Protocolado em: 29 set. 2008. Aceito em: 24 jun. 2010. 